\title{
Esa soy yo: un recorrido por la intimidad en Teoría de la gravedad de Leila Guerriero
}

\section{That is me: a Walkthrough Intimacy in Teoría de la gravedad by Leila Guerriero}

\section{Resumen}

A diferencia de las crónicas modernistas del siglo XIX -como las de Rubén Darío o José Martíen donde se defendía el lugar «yo» del sujeto (Rotker), en el periodismo narrativo de Leila Guerriero, la subjetividad se expresa en las formas elegidas para contar; es decir, en cada uno de los procedimientos que construyen su práctica de escritura, más que en lo gramaticalmente manifiesto. En Teoría de la gravedad (2018), el discurso se codifica mediante un uso particularmente poético del lenguaje. En estas crónicas autorreferenciales (o relatos-perfiles), la autora evoca su infancia, su juventud y los días contemporáneos a su escritura desde una perspectiva que pretende indagar la propia intimidad, a partir de una dinámica precisa del «mirar» y del «contar». Se auto-representa en el espacio de la narratividad como sujeto-límite (por momentos, borroso) entre un interior subjetivo y un exterior narrable, a fin de encontrar otro sitio en la escritura donde pueda cobijar-se en el proceso del devenir más que en el del ser.

Palabras claves

Crónica; intimidad; espacio biográfico; subjetividad; identidad.

\begin{abstract}
Contrary to the 19th century's modernist chronicles - such as Ruben Darios's or José Martí'sin which the "self" of the subject was defended (Rotker, 1992), in Leila Guerriero's narrative journalism, the subjectivity is expressed by the ways of telling chosen by her; i.e., in each process that form her writing practice, more than what is grammatically expressed. In Teoría de la gravedad (2018), the speech is codified through a particularly poetic use of the language.
\end{abstract}


In these self-referential-chronicles (or profile-short story), the author recalls her childhood, her youth and her writing days from a perspective that intends to question her own privacy, through a precise dynamic of "looking" and "telling". She represents herself in the narrative space as a limit-subject (at times, blurred) between a subjective interior and a tellable exterior, with the final purpose of finding another writing-place that can shelter her in the process of becoming more than in that of being.

Keywords Chronicle; intimacy; biographical space; subjectivity; identity.

A las aves migratorias se les desarrolla un agudo sentido del tiempo porque vuelan de un presente a otro y lo primero que perciben cuando llegan es el recuerdo del otro presente.

Josefina Ludmer

Ella se mira a sí misma -se ha acercado a su imagen. Se acerca aún más. No se reconoce muy bien. No entiende qué ha pasado. Lo entenderá aún más tarde: tiene ya el rostro destruido de toda su vida.

Marguerite Duras

Lo dijo en voz alta, por si acaso no estaba totalmente sola; pero también lo dijo como para sí misma, en ese punto remoto de la conciencia y de olvido en el que la voz alta y la voz baja ya no se distinguen bien, ni se distinguen bien tampoco lo que se dice hacia afuera y lo que se dice para adentro.

Martín Kohan

\section{Una aproximación a Leila Guerriero}

En la entrevista realizada por el periodista mexicano Julio Patán, para el programa televisivo Es la hora de opinar, en el mes de julio de 2020, Leila Guerriero suelta una pregunta que resulta disparadora para comenzar a hilar la propuesta que nos convoca: «¿En qué le puede interesar esto [sus columnas] al 
lector?». ${ }^{1}$ En una suerte de pensamiento en voz alta, la escritora y periodista argentina destila una genuina preocupación en torno a la fundamentación de su proceso de escritura como práctica de interés público. Se cuestiona en qué aspectos (y en cuáles no) puede interpelar al lector, captar su atención para que se sienta interesado en leer las treinta líneas que conforman las columnas que, sábado por medio, publica en el diario El País, de España. Leila continúa con su discurso: dice que, a veces, no se le ocurre qué escribir, pero que tiene que hacerlo porque no puede entregar un espacio en blanco para que funcione como texto. Y, entonces, confiesa: su deseo es siempre incomodar al lector, molestarlo con cuestiones y aspectos que resulten «desobedientes»o «salvajes», porque está en su naturaleza ser insolente e indagar, mediante esa insolencia, la historia, la actualidad y las personas en su mundo.

Algunos de estos textos personales — escritos entre los años 2014 y 2019 y a los que se refiere en la entrevista - fueron recopilados, reordenados y publicados en Teoría de la gravedad en 2019, en Barcelona, España. Es este libro el que nos convoca y nos invita a reflexionar en torno a la práctica de escritura de Guerriero. Concretamente, nos interesa analizar la construcción de un discurso de la intimidad, transversal a todos sus relatos. Para ello, tendremos en cuenta las formas mediante las cuales se manifiesta la subjetividad del yo-narrador(a) en el texto para dejar a disposición parte de su vida personal. Como efecto de lectura inicial y general, aseveramos que dicha escritura permanece codificada mediante un uso poético del lenguaje que le sirve para contar los detalles certeros de una infancia apaciblemente evocada y las controversias, aciertos y fracasos del mundo cotidiano. ${ }^{2}$ Siguiendo

${ }^{1}$ Habrá otros momentos en los que citaremos las palabras textuales de la autora que fueron transcriptas de dicha entrevista para el caso. La fuente se consultó por última vez el 21/01/2021 y está disponible en la bibliografía citada al final.

${ }^{2}$ La cursiva es nuestra. El término «contar» está marcado ya que pretendemos resignificarlo en dicho contexto como un proceso de referencia a los propios sucesos vitales de la periodista, a partir de la narración de experiencias personales pasadas y de marcaciones de subjetividad del yonarrador específicas. «Considerar», «importar» y «disponer» son también algunos de los verboides que sugiere la RAE cuando se busca dicho término; al caso, resultan sugerentes para aludir a la propia práctica de escritura que pone en juego Guerriero en su quehacer literario, es decir, la preparación anterior de lo que, luego, se presentiza en el discurso. Y es que Teoría de la gravedad 
esta línea de análisis, nos detendremos también en pensar el uso de la memoria como artificio discursivo, esencial y oblicuo, que posibilita presentizar el pasado en la narración y articularlo como parte de la intimidad (e identidad) del yo, con el objetivo de interpelar al lector e interesarlo con $-\mathrm{y}$ - en el decir.

\section{Intimidad, subjetividad, identidad}

En El espacio biográfico: dilemas de la subjetividad contemporánea (2007), Leonor Arfuch toma prestado el término «espacio biográfico», acuñado por el francés Philippe Lejeune, para introducir y referir a las «narrativas del yo» que comenzaron a tener mayor preponderancia a partir de 1980. La autora explica las diferencias entre lo público, lo privado y lo íntimo, teniendo en cuenta el marco socio-cultural y económico que englobó el surgimiento de las narrativas autorreferenciales por entonces. En este sentido, realiza un estudio comparativo de diversas producciones autobiográficas inveteradas para arribar a ciertas ideas respecto de esta «paulatina expansión de subjetividades» (19) que iba haciéndose cada vez más perceptible durante ese período de tiempo. Llega a una conclusión: dicha forma de narrar permanece profundamente anclada en una asunción del «yo» $\mathrm{y}$ atestiguada por una insistencia en las vidas reales, «por la autenticidad de las historias en la voz de sus protagonistas, por la veracidad que el testimonio imponía al terreno resbaladizo de la fícción» (21). Así, el concepto de "espacialización" de la autora nos permite esbozar un piso sólido en el cual situar la escritura de Guerriero, no haciendo caso al eje temporal -pues, las crónicas a analizar pertenecen a la primera década del siglo XXI-, pero sí a las formas elegidas - y compartidas - para la enunciación. ${ }^{3}$ Como un estilo que se perpetúa en el tiempo

recopila las columnas que, en palabras de Pedro Mairal, conforman una «mitología personal [...] una exploración del anonimato en la multitud» de la autora (XI).

${ }^{3}$ Según Arfuch, "una espacialización, como señalara más arriba, donde confluían en un momento dado formas disímiles, susceptibles de ser consideradas en una interdiscursividad sintomática, de por sí significante, pero sin renuncia a una temporalización, a la búsqueda de herencias y genealogías, a postular diversas relaciones en presencia y en ausencia" (El espacio 22). 
y que abarca diversas finalidades políticas, sociales, culturales, entenderemos su escritura en tanto «espacio biográfico» de confluencias personales. ${ }^{4}$

La crónica que abre Teoría de la gravedad lleva por título «El pacto» y comienza de la siguiente manera: «Aquí yo, otra vez, arrastrándome en el pantano de los rotos o flotando feliz entre la euforia de los vivos, idéntica a mí, la muy sincera, la muy falsa, la esquiva, la insensible, la mísera, la idiota [...]» (5). La enunciación es determinante e instala, desde el inicio, el punto desde donde el «yo» contará. ${ }^{5}$ El uso del deíctico «aquí» no refiere precisamente a un lugar físico en el que se halla la voz narradora, sino más bien, a un espacio de encuentro entre el sujeto y el mismo proceso de intervención de esa hoja en blanco que mencionamos en el primer párrafo. Se trata de la apertura de una zona del «decir» que permanecerá móvil y blanda para que la voz pueda expandir(se) en cada una de las crónicas autorreferenciales. Esta elección se refuerza con la utilización del pronombre personal en primera que ocupa un puesto bien marcado en la narración y «se hace cargo» de aquello que nombra. Sin embargo, la subjetividad aparentemente bien delimitada de ese «yo» comienza a desdoblarse de inmediato en una tercera persona, rompiendo el molde elegido desde el inicio y proyectando la carga de la voz enunciadora en «otra», caracterizada de forma peyorativa. La

${ }^{4}$ Resulta sumamente compleja la clasificación genérica de los textos analizados en el presente artículo. Si bien conocemos que se trata de columnas de opinión -textos en los que es dable expresar, con fundamentada libertad, ciertos atributos del yo-, es también posible pensarlos como crónicas personales. En este sentido, es pertinente retomar las palabras que Julio Ramos postula en el capítulo cuarto de Desencuentros de la modernidad en América Latina: literatura y política en el siglo XIX (1989): «[...] la crónica -en su disposición formal, tan conflictiva- representa la pugna de autoridades, la competencia discursiva, presupuesta por el «interior» poético. El interior, el campo de identidad de un sujeto (literario, en este caso), sólo cobra sentido por oposición a los «exteriores» que lo limitan, que lo asedian, si se quiere, pero que a la vez son la condición de posibilidad de la demarcación de su espacio [...] El límite permite reconocer la especificidad del interior: el énfasis del «estilo» [...] sólo adquiere densidad en proporción inversa a los lugares «antiestéticos» en que opera» (205). Oscilaremos entre ambas nomenclaturas a lo largo del trabajo, teniendo en cuenta las operatorias formales y discursivas que proponen los relatos, en tanto espacios de encuentro entre el "interior" poético y la zona "extratextual".

${ }^{5}$ Resulta interesante re-pensar la idea de "contar", por un lado, como ejercicio de numeración (visible, al caso, en el plano textual, en el que la autora enlista una serie de posibilidades de su "yo") y, por otra parte -y paralelamente-, "contar" en tanto operatoria de referir o relatar sucesos de su vida. 
autorreferencia se traslada hacia un lugar diferente y, desde la aparente neutralidad, intenta también definirse.

La intimidad se abre, en este relato en particular, como una grieta que dirige la intención hacia la reflexión de la propia Leila sobre su vida, sobre su yoperiodista y su yo-persona (si es que, al caso, puede hacerse esta distinción). ${ }^{6}$ Enumera cualidades negativas que intensifican la propia percepción de quien se instala como narradora de los hechos. ${ }^{7}$ Entre la pretendida neutralidad del «yo»o, en todo caso, entre el deseo de su propio «alejamiento», se cuela, nuevamente, la primera persona y se insiste en la referencia -adrede- a ese pronombre como un intento de indagación sobre sí misma: « [...] la agresiva, la suave, la tan suave, aquí yo, yo, yo, la egocéntrica, la narcisa, la modesta, la muy humilde [...])» (5). Dicho vaivén pronominal es la traducción explícita del deseo de descubrir y de desplegarse ante ella, la escritura y los propios lectores en un solo espacio. Guerriero cierra esta crónica parafraseando una cita de Andrés Felipe Solano y dice: «Vengo aquí. Saqueo mi vida. Ahí la tienen» (6). Otra vez, en un acto decisivo, el «yo» se ubica y «va» al encuentro con la escritura -y consigo misma- en una tentativa de apoderarse de todo lo disponible; cuenta para los demás, se abre y expone la búsqueda de su propia identidad, partiendo desde lo particular hacia lo universal.

${ }^{6}$ Al respecto, citamos a Paula Sibilia para repensar las complejas variables del yo en el plano autobiográfico: "Esto fue lo que conjeturó el crítico literario Philippe Lejeune en los años setenta del siglo XX: las obras autobiográficas se distinguen de las demás porque establecen un "pacto de lectura" que las consagra como tales. ¿En qué consiste ese pacto? En la creencia de que coinciden las identidades del autor, el narrador y el protagonista de la historia contada. En suma, si el lector cree que el autor, el narrador y el personaje principal de un relato son la misma persona, entonces se trata de una obra autobiográfica. [...] Pero además no deja de ser una ficción, ya que, a pesar de su contundente autoevidencia, el estatuto del yo siempre es frágil. Aunque se presente como "el más irremplazable de los seres" y "la más real, en apariencia, de las realidades", el yo de cada uno de nosotros es una entidad compleja y vacilante. Una unidad ilusoria construida en el lenguaje, a partir del flujo caótico y múltiple de cada experiencia individual." (37).

${ }^{7}$ Haciendo caso a la cita anterior, entendemos que la mayoría de los textos pueden ser leídos en tanto testimonios autobiográficos o personales y, entonces, las categorías de autor y narrador pueden ser concebidas desde una perspectiva ambivalente, indistinta y, paradójicamente, conflictiva y compleja. 
Como observamos, la curiosidad del lector se mantiene viva en tanto existe una fluctuación sincera de ese «yo» por el deseo de auto-definirse en una mecánica sutil de develamiento de la información. La «especificidad de lo íntimo», tomando las palabras de César Aira (7), se va socavando por cuanto la voz narradora va hallando diferentes ocasiones para (re)pensarse en la discursividad. Lo que Beatriz Sarlo llama el suspenso de lo que «continuará» efectivamente permanece en el plano de la enunciación como un modo de desvelamiento personal y, finalmente, como una manera de mostración del «yo» que permite ser leída ya como ficción, ya como realidad. Leila guiña el ojo a los lectores y mantiene suspendida la determinación de su propia subjetividad cada vez que puede: «La personalidad como algo totalmente ficticio, de construcción, es una máscara. Y que, como supongo que les sucede a todos, en ocasiones me siento una máscara» (58). La autorreferencialidad, el anhelo por correr el propio velo de lo íntimo, vacila dependiendo de la trama a la que refiere cada columna. Y entonces, nos encontramos con que el sujeto intenta definir su identidad por su pertenencia a diversos territorios ("Literaturas" 42). Leemos, consecuentemente, la necesidad de decir-se y negar-se simultáneamente, en una dinámica sesgada de autodescubrimiento. Dicha búsqueda personal no deja de ser un acto de exhibicionismo por parte del yo-narrador que tiene su correlato en la curiosidad de quienes leen el texto (Aira 8). Al contar se rompe con el precepto que de intimidad se tiene, como lo secreto, lo oculto, como parte de la reserva indecible, y se crea una relación-otra que considera al receptor como partícipe del proceso de discursividad, como cómplice activo del decir: «Ahí tienen», suelta Guerriero (6) y se funda, entonces, el pacto con el lector (tal como indica el título primero). A propósito, es acertado aquí referir a la idea de "extimidad” que Paula Sibilia recupera de Jacques Lacan, para aludir a la operatoria, aparentemente contradictoria, de la exhibición de la propia intimidad. En La intimidad como espectáculo, la antropóloga afirma que la “subjetividad no es algo vagamente inmaterial, que reside 'dentro' de usted [...] la subjetividad es necesariamente embodied, encarnada en un cuerpo; también es siempre embedded, embebida en una cultura intersubjetiva” (20). Así, los límites 
entre lo público, lo privado y lo íntimo se vuelven difusos y la mostración del "yo" apuesta, entonces, a su "legitimación moral" y no a la producción de una carga peyorativa.

\section{Hacia una intimidad democratizada}

El segundo relato compilado se estructura mediante una oración que se repite, una y otra vez, y que pretende fortalecer esta alianza discursiva, con el fin de abrir nuevos espacios para la comunicación de lo personal (y lo universal). Comienza así: «Supongo que creen que...» (7) y le sigue una enumeración de actividades propias de la cotidianeidad como viajar, conocer gente, estrenar ropa, cocinar, salir con amigos, escuchar música, entre otras. El relato empieza a incomodar cuando seguimos leyendo y nos encontramos con una suerte de listado de argumentos que se distancian de lo rutinario y se intensifican en un intento de indagación sobre el existencialismo humano más profundo: «Supongo que creen que la vida les va a durar toda la vida. Que la alegría les va a durar toda la vida» (8). La sucesión de acciones, en efecto, está dotada de subjetividad pronominal, aunque se juegue con el artificio de trasladarlas a las creencias de los lectores. Y es que, a diferencia de la primera crónica, acá el procedimiento de apertura de «lo íntimo» consiste en proyectar los propios pensamientos, dudas y reflexiones en consciencias ajenas. La interpelación se vuelve, en estas columnas, uno de los instrumentos activos para la construcción del relato $\mathrm{y}$, consecuentemente, se instala un nuevo vínculo con lo narrado: pues, late en la enunciación la apelación al otro para el desvelamiento de la propia intimidad. En este punto, Guerriero pareciera prever el tipo de espectador de su obra, lo estudia, para delinear luego su propia literatura; ya que, como predica César Aira, «[...] la intimidad: es lo que le pasa a uno y les interesa a muchos» (12). Así, escritura y lectura se vuelven dinámicas reversibles, recíprocas e interdependientes; finalmente, una «práctica territorial de lo cotidiano» ("Literaturas” 42) que puede o no ser leída como literatura. 
Por momentos, la interpelación a los lectores se hace visible no precisamente en un llamado directo a la segunda persona, sino que se elige difuminar la voz autorreferencial en voces diversas que podrían ser parte de pensamientos continuos de otros agentes sociales y, entonces, el «yo» se despedaza y se exterioriza en otras personalidades. ${ }^{8}$ En la columna «Era la vida» encontramos, de nuevo, el recurso de la repetición de una fórmula sintáctica que hila todo el texto. El verbo «Debería...», conjugado en condicional, posterga la obligación, la transforma en deseos o en actos posibles y se vuelven a puntear estados, emociones, sensaciones, experiencias. Leemos, por ejemplo: «Debería ir a recitales. Debería invitarla a cenar, invitarla a un bar. Decirles que soy gay. [...] Debería cambiar de analista, conseguir un analista, dejar de ir al analista» (9). Acá la autorreferencialidad parece borrarse y, por tanto, el juego con la intimidad busca otro espacio para explicarse. La voz narradora se abre en un abanico de posibilidades, se despersonaliza y encuentra, en la diversidad de fórmulas opuestas o propuestas negadas -e hipotéticas-, la probable empatía o identificación del lector. No obstante, este afán de «querer abarcarlo todo»-evidente en el procedimiento de la enumeración- no peca de la omnisciencia tradicional; dicha escritura parte de una práctica introspectiva y personal que se hace con los lectores y que, asimismo, se desplaza por los múltiples y posibles lugares de enunciación, puesto que es el «yo» el que se expande fuera de sí y no quien «observa» ese exterior desde la mera potestad narrativa. Al caso, retomamos las palabras de Leonor Arfuch, quien afirma que la

${ }^{8}$ A propósito de la segunda persona, cabe mencionar que en Teoría de la gravedad encontramos dieciocho columnas, ordenadas una tras otra, tituladas como "Instrucciones" y que exhortan explícitamente a los lectores a realizar acciones enmarcadas en el contexto de lo rutinario. A diferencia del efecto de extrañamiento (de la literatura de Julio Cortázar, por ejemplo) en las columnas de Guerriero percibimos una intención de "acercamiento" o "detenimiento" de la acción cotidiana hacia una evocación existencialmente más profunda (algo así como el ofrecimiento de órdenes para la "realización consciente" de los acontecimientos de la vida y la consecuente reflexión de aquello que se lleva a cabo). Es interesante referir a estos relatos porque, en algún punto, siguen una dinámica similar a la que se propone en el resto de las crónicas, indagan sobre otras formas de narrar y sobre otros modos de apropiación y demostración de lo íntimo. Pormenorizar al caso sería interesante, pero no nos detendremos en ello en este trabajo. 
imposibilidad de adecuación, ese desliz del sujeto en exceso o defecto dicho de otro modo, su irrepresentabilidad en una posición- permite desplegar una concepción no esencialista de la identidad, que enfatiza la incompletud, el inacabamiento y, por lo tanto, es más apta para dar cuenta de la creciente fragmentación contemporánea. (“Problemáticas”22)

El espacio aparentemente cerrado de lo íntimo se abre en la reclamación de los lectores como copartícipes de esa intimidad, como cómplices de una narración que puede ser concebida indiferentemente como ficción o realidad. Se los busca también para la construcción de un relato que genere nuevos códigos de lectura. La simple escritura autorreferencial puede insinuar, asimismo, un recorrido acotado a la propia construcción de la subjetividad. Por lo tanto, apelar al otro para reclamar su propia reflexión sobre lo que se cuenta, expande el horizonte de lo autobiográfico -aunque, muchas veces, persista vedado o vibrante entre despersonalizacioneshacia otros espacios más amplios, fuera del cuerpo escribiente y extrapolados en el público colaborador del relato. En este sentido, podríamos pensar en una intimidad «con», en una intimidad comunitaria, compartida, democratizada en el espacio de la discursividad: la confesión de lo íntimo busca aliados. No prevalece el ánimo egocéntrico en la literatura de Guerriero -aunque la singularidad se explicite, en reiteradas oportunidades, bajo el pronombre «yo»-, sino que su narración despliega las posibilidades de su propia consciencia ambivalente y, con ella, la especulación de estar estudiando a los receptores en la misma dinámica discursiva. La originalidad de su forma radica en la intención de buscarse en el propio plano textual, en un ejercicio que excede la mera intención "mostrativa" de sí misma (en palabras de Sibilia, el "show del yo"). Más bien, la autora intenta encontrar, en la materialidad de la propia escritura, un espacio para indagar sobre su subjetividad e interpelar, latente y constantemente, al lector mediante operatorias de revisión personales. En este sentido, sería mejor referirnos más que al término de "confesión" (entendida esta como "demostración" o "reconocimiento" de un error o de lo previamente no aceptado), al de "apertura" del yo, en tanto dicha acción 
implica generar un otro-espacio de cruce entre un interior poético y un exterior (compartido con otros agentes) que permanece en constante estado de conformación.

\section{Las máscaras del «yo»}

El corrimiento del «yo» no sólo se produce mediante una intuición por democratizar la intimidad de quien narra en diversos agentes sociales. También, el deslizamiento de la primera persona está puesto en un juego de tercerización pronominal en el que la autora pareciera revisarse a través de una lente cinematográfica. En «Máscaras» nos encontramos con frases como: «Esa soy yo jugando con dos gatas. Esa soy yo cenando con tres amigos y riéndome como un lobo [...] Esa soy yo...» (59). La repetición del sintagma «esa soy yo» instala en el relato el lugar de posicionamiento de la primera persona (como una «otra» alejada en tiempo y espacio del sujeto que escribe) y, consecuentemente, el efecto de ir recorriendo pequeños mosaicos, pequeñas tomas fotográficas de la vida de la escritora. En esta dinámica de desdoblamiento, Leila juega a verse a sí misma desde fuera y, entonces, elige adoptar el papel de espectadora de su propia vida, en una mecánica semejante a la que sigue el lector con cada uno de sus textos. Este intento por neutralizar la autorreferencialidad responde al deseo de no saturar la narración con constantes alusiones personales y democratizar el espacio de lo íntimo, los lugares incómodos de la cotidianeidad -como ya hemos mencionado anteriormente- que, en este caso particular, refieren a la práctica profesional de la autora, a su taller de escritura, a su escritorio. Pero, además, este modo se entiende como un fuerte deseo de «representatividad», en tanto

[...] el qué y el quién de la apuesta identitaria se delinea justamente en la forma del discurso (considerado éste, en sentido amplio, como toda práctica significante), no solamente en aquellos relatos centrados en la 
(propia) subjetividad sino también en los marcados incluso con el «efecto de real» más canónico de la historia o la antropología (Arfuch, "Problemáticas" 25). ${ }^{9}$

Entonces, dicha representatividad se construye, ocasionalmente, en un movimiento oscilante que permite a la autora tomar el papel de observadora de su propia vida y, asimismo, generar el espacio para acompañar al público en el mismo proceso de descubrimiento de la «verdad». ${ }^{10}$ La operación de escribir pareciera dejar de ser un mero acto de complacencia personal omnipotente para pasar a ser un «vaso comunicante» de realidades (y verdades) diversas, exteriores y, finalmente, públicas.

\section{Leer literatura, escribir el pasado}

El lugar de la literatura es también, en esta compilación, una punta ostensible para la construcción de la intimidad y de la propia identidad. En La lectura: una vida..., Daniel Link condensa una verdad, en pocas palabras, que nos servirá al caso: «No sé lo que soy, pero sé lo que he leído (8). Algo parecido sucede con las crónicas de Guerriero. Predomina una operatoria constante en la que reitera frases leídas; abre y cierra muchos de sus textos con versos de diferentes autores como modo de legitimar su propia práctica literaria y/o periodística y, asimismo, como una forma de compartirla, de exhibir la pertenencia a ella (tomando el término propuesto por Josefina Ludmer, a propósito de las literaturas postautónomas). En ocasiones, hace uso de la literatura como un trampolín, como una excusa, para desatar y comenzar a desandar su propio texto. Leemos frases del tipo: «No siempre tengo cosas para decir. Entonces, a veces, me pongo a leer a Elizabeth Bishop»

\footnotetext{
${ }^{9}$ El resaltado en cursivas pertenece a la fuente citada.

${ }^{10}$ Frente a la idea de «verdad», Guerriero postula en la entrevista que su deseo es «Discutir un poco esas ideas que parecen precocidas y que uno tiende a digerir como si fueran verdades y, a veces, no lo son y es necesario mirar abajo de la superficie».
} 
(Guerriero 13); «Estoy releyendo It, de Stephen King [...])» (29); «Leí estos versos de Stella Díaz Varín, poeta chilena [...]» (31); «Leo, hacia el final de Un hombre enamorado, la temible y fabulosa novela del noruego Karl Ove Knausgard, esta frase [...]» (95); «Leo el último volumen del diario de Ricardo Piglia, que acaba de publicarse» (183).

Por momentos, encuentra en lo raso, en el vaciamiento del no-poder-decir y en el escepticismo sobre su propia identidad (que involucra a su profesión, también), el espacio para anclar la literatura y la excusa para auto-proyectarse: «A veces pienso que mi oficio no es otro que el de venir aquí y contrabandear poemas que escribieron otros» (82). La autora nos sitúa en el espacio de la creación; nos revela el work in progress de los breves textos -a los que se refiere como «baldositas»- y, finalmente, instala otro vínculo con lo narrado. Mediante el uso del tiempo presente, actualiza su discurso, a medida que avanza con la escritura, y despunta o excava todos los rincones de su espacio biográfico: su quehacer profesional, su vida sentimental, los sueños e, incluso, su propia infancia y juventud. No representa, por tanto, su propia vida, porque ésta ya es pura representación en la discursividad ("Literaturas" 42). A tal efecto, la literatura, lejos de ser sólo un objeto-excusa para narrar, se transforma en el modus operandi de las crónicas. Guerriero no sólo abre un abanico de citas de versos, frases y nombres propios de la comunidad letrada, sino que abraza los modos de lo poético para contar. Y esta práctica es también parte de la manifestación de su intimidad. $\mathrm{Su}$ propia escritura se construye en un espacio fronterizo, en el que la literatura va y viene como parte de la identidad de la autora: contar lo que uno lee es, entonces, definirse.

Así, el revés de la intimidad -y de la identidad- queda expuesto en la medida en que la voz narradora va indagando en el pasado, mediato o inmediato, a fin de encontrar otro sitio en la escritura donde pueda cobijar-se en el proceso del devenir más que en el del ser (Arfuch, "Problemáticas" 22). Por ello, cuenta desde la experiencia sensible de las cosas, desde la huella del sentimiento, ya que, tal como afirma Beatriz Sarlo, la perspectiva emocional es el rostro amigable de las 
sociedades del mercado (113). Encuentra refugio en los recuerdos, pero no como puros conteos o sucesiones de acontecimientos autorreferenciales, sino como intentos de apropiación y refracción de su propia experiencia vital, porque «el pasado nunca termina de pasar» (Guerriero 64). La autora vivifica lo acontecido, nuevamente, bajo la misma operatoria: referir a sucesos en un arte de presentización que sea útil para buscar cierto sentido trascendente de-y-en la vida. El uso de la memoria como artificio discursivo es el procedimiento transversal para llevar a cabo su intención y para construir un sentido de percepción particular que, por supuesto, involucra siempre el espacio de lo íntimo, tanto para percibir la realidad como para contarla.

En las crónicas referidas a su infancia y juventud, predomina la trama descriptiva más que la narrativa. Esta particularidad discursiva puede justificarse con la intención de la autora de querer acercarnos otro tiempo y otro espacio para ponerlos en funcionamiento en el relato, presentizar el pasado, como hemos referido antes. Rememorar, para Guerriero, implica también abrir una puerta a la intimidad, a los secretos propios, a la reserva familiar. Queda a la vista que es más importante traernos dicho pasado a la escritura mediante la creación de una atmósfera sensible, plagada de metáforas y efectos sensoriales, que la sola enumeración de acontecimientos sobre su niñez. Al caso, retomamos la idea que Tamara Kamenszain postula en Una intimidad inofensiva e imaginamos el proceso inverso en el discurso de Guerriero: y es que su narrativa necesita pedirle prestado algo a la poesía para expandirse y, más precisamente, para referir a la propia historicidad del sujeto (8). ${ }^{11}$ Sucede que, frente al deseo de ir construyendo la propia

${ }^{11}$ La cita textual y completa predica: "Es en este punto donde las aventuras de la poesía y las de la narrativa se vuelven a encontrar. Pero ahora es la poesía la que parece necesitar pedirle prestado algo a la narrativa. Es que ese poema-sujeto, en su actividad desbordada, se dispone a expandir su campo de acción y para eso necesita echar mano de recursos que lo conecten con su propia historicidad. Así es como empieza a recurrir a los tiempos pretéritos, aliados indiscutibles de la narrativa. Porque si es cierto que la poesía, aunque esté escrita en pasado, se escribe siempre en presente $\mathrm{o}$, para decirlo en otras palabras, si es cierto que la poesía presentifica el presente, ahora el pretérito vendría a tratar de impedir que el yo quede preso de un presente puramente enunciativo." (Kamenszain 8). 
subjetividad en la narración, se irán solapando diversas estrategias para una mostración más o menos sincera del «yo».

Las imágenes sensoriales son, entonces, parte de la construcción de los ambientes en los que se funda la autora (en cada una de las crónicas) y funcionan como modo de aproximarnos también a su propia forma de experimentación de la realidad. Y especialmente, en la dinámica del recuerdo, lo que queda en la memoria es la huella, el resto sensorial de aquello que pasó. Es con este resto que Guerriero escribe y traza el espacio personal, a partir de metáforas y detalles asertivos, precisos como un latigazo, ya que «el qué y el quién de la apuesta identitaria se delinea justamente en la forma del discurso» (Arfuch "Problemáticas" 25). Leemos frases en donde la vista es el medio de aprehender (y rememorar) el contexto: «Más de veinte años después de aquella noche caminé hasta ese banco bajo la luz lechosa del día, bajo el ojo glauco del sol, sintiendo una espuma negra rozarme los flancos [...]» (Guerriero 66). Tal como si se tratara de una cámara cinematográfica, el «yo» re-visita los espacios, al tiempo que nos va paseando por una narración bien descriptiva, blanda, en la que todo el cuerpo funciona para contar. Otro ejemplo claro, en el que el procedimiento artificioso de "hacer memoria" se une con la propia práctica discursiva, es el siguiente:

[...] escribo rosa chicle y borro, escribo rosa dior y borro, escribo rosa fondant de torta de cumpleaños y entonces sí, recuerdo aquellos cumpleaños infernales, los gritos de los niños, el color de las grajeas [...] y me vuelve el olor del cloro en la piscina, $[\ldots]$ los susurros mientras dormían los adultos $[\ldots]$ el mundo envuelto en un guante de calor $[\ldots]$ y todo eso no alcanza para decir nada. (80)

El ejercicio consiste en presentizar el pasado en su escritura, traerlo a colación en un acto de apertura de la subjetividad y de la intimidad recordada y recordable por la periodista. Mediante verbos en presente ("escribo"; "vuelve"), se actualiza lo vivido en el plano enunciativo. Así, el lenguaje -la palabra- funciona 
como bisagra y está articulada para facilitar el acceso a los lugares más profundos del "yo", en este caso, al propio pasado. El significante "rosa fondant de cumpleaños" es la llave que abre el recuerdo íntimo y conduce al secreto, al pasado mediato y, por lo tanto, admite significar el resto de la frase: los ojos se posan en el color rosa, capturan el de las grajeas, el oído presente sigue atento a los gritos y los susurros de los niños, y el olfato capta el cloro de una pileta.

Porque, como afirma Leonor Arfuch, «es siempre a partir de un «ahora» que cobra sentido un pasado, correlación siempre diferente -y diferida- sujeta a los avatares de la enunciación» ("Problemática” 25). En este mundo paralelo e íntimo de Guerriero, se reconoce la imposibilidad de exteriorizar una verdad que funcione, sobre todo, para sí misma, porque el lenguaje es insuficiente: «Y todo eso no alcanza para decir nada». La autora se vale de la mayor cantidad de recursos para poder decir y significar; pero la palabra, finalmente, la defrauda, la traiciona (no existe una mayor representatividad, según Arfuch). Hay un deseo explícito por correr o romper la barrera de lo íntimo en el plano enunciativo, a medida que se sigue escribiendo: y es que en el contar se desarrolla el propio develamiento de la identidad. Pero, a pesar del detalle de los sonidos, de las luces, de los olores, de la precisión de nombres propios, de las fechas y las horas, de las citas textuales, permanece un deseo utópico, una búsqueda deseante de la imposible comunicación consigo mismo, porque, en definitiva, la intimidad culmina en uno solo (Aira: 8). ${ }^{12}$

Finalmente, en un acto de justicia, Leila elige cerrar el libro con una columna que se titula «Empezar» y que tiene como última línea la siguiente: «Regresar, la única forma de seguir adelante. Aquí, donde todo comenzó, escribo. Empiezo. Allá vamos. (Qué curiosidad)»(202). La dinámica de la escritura,

\footnotetext{
${ }^{12}$ Paradójicamente, la reivindicación de la escritura hace eco en las crónicas que se detienen en la reflexión sobre su propia profesión. Es en ellas cuando, a fin de cuentas, se halla la justificación de la vastedad de procedimientos apropiados, del detenimiento poético en cada uno de los relatos y del compromiso intrínseco del «yo» por agotar, en cada línea, la carga del lenguaje. El sujeto no titubea ante la certidumbre de saberse ser-escribiente y entonces leemos confesiones del tipo: «Sabía lo que quería hacer -escribir, escribir-, pero no cómo se hacía para vivir de eso» (21); «A veces preguntan por qué uno escribe. Supongo que por cosas como éstas» (196); «Corro para escribir. Escribo porque corro. Porque es igual de inútil, igual de necesario, igual de pavoroso» (198).
} 
entendida como un acto de reflexión sobre la propia vida, opera, además, como ejercicio recursivo e infinito, expresión catártica-introspectiva de las propias vivencias y como mecánica que deconstruye el camino de ficción para posicionar al «yo» en la materialidad de la propia extroversión.

\section{Punto de gravedad}

El trabajo previo que la autora lleva a cabo antes de escribir sus crónicas es también evidente en Teoría de la gravedad: no se trata entonces de entrevistas a otras personas y personalidades -como sí se lee en sus crónicas perfiles, por ejemplo-, pero se percibe el tiempo anterior ocupado en la reflexión y el detenimiento introspectivo (y retrospectivo) de quien desea escribir algo que (la) interpele y, asimismo, deje un resto significante en la memoria del lector (aquello que, previamente, dejó un resto significante en la memoria de la autora). Se trata de una especie de cadencia en la operatoria de lectura. En este sentido, podemos hablar metafóricamente de sus textos como «cajas de resonancia» que amplifican (o vacían) los sentidos sugeridos por ella y, al mismo tiempo, colaboran con la modulación de efectos posteriores de lectura. Busca aproximarse al público lector $\mathrm{y}$, en todo caso, interesarlo en la esporádica incomodidad de su discurso, al tiempo que utiliza la palabra como diván, como liberación, como catarsis propia. Ya que, revisar la vida desde los rincones, hacer foco en lo que no se ve (o en lo que no se quiere dejar ver), conlleva entregarse a cierta deconstrucción subjetiva y, por ende, también, invita al lector a examinar diversas huellas de sentido en el texto y en su propia intimidad. ${ }^{13}$

Finalmente, Leila Guerriero canta «con una voz limpia, satinada y heroica. Una voz ambarina, desnuda, severa, enorme, un canto como un trozo de hueso» (43). No hay inmediatez en su escritura (aunque la narración proponga una lectura

${ }^{13}$ Según Peter Krieger, sobre Jacques Derrida, «la deconstrucción no busca 'sentidos' sino huellas de ideas» (183). 
ágil y accesible), sino más bien un desprendido detenimiento discursivo, una delicada espera en cada idea para certificarla con emociones, sensaciones y memorias personales. Leila dedica tiempo a las imágenes que esboza y escribe desde el propio vestigio de los sentidos o, en todo caso, de los sentimientos y sensaciones. Su (post)literatura postula una intimidad pensada, reflexiva y simultáneamente, espontánea, pero no por ello arrebatada. Así, esta forma particular de evocar lo cotidiano, los tiempos, los sueños, las vivencias, la manera de desprender su «paisaje íntimo» es, sobre todo, el punto de gravedad de su escritura.

\section{Bibliografía}

Aira, César. «La intimidad». Centro de Estudios de Teoría y Crítica Literaria, boletín 13/14, diciembre 2007 - abril 2008, pp.7-12.

Arfuch, Leonor. El espacio biográfico: dilemas de la subjetividad contemporánea. Buenos Aires: Fondo de Cultura Económica, 2007. . «Problemáticas de la identidad». Identidades, sujetos y subjetividades, comp. por Leonor Arfuch. Buenos Aires: Prometeo, 2002, pp. 19-41.

Duras, Marguerite, El amante de la China del Norte, Barcelona: Narrativa Actual, 1993.

DRAE: Real Academia Española (2021): Diccionario de la lengua española. Madrid: Espasa-Calpe.

Guerriero, Leila. Teoría de la gravedad. Barcelona: Libros del Asteroide, 2019. Kamenszain, Tamara. Una intimidad inofensiva: los que escriben con lo que hay. Buenos Aires: Eterna Cadencia, 2016.

Kohan, Martin. Dos veces junio. Buenos Aires: Editorial Sudamericana, 2002.

Krieger, Peter. "La deconstrucción de Jacques Derrida (1930-2004)". Anales del Instituto de Investigaciones Estéticas vol. 26, 84, 2004, pp. 179-188.

Link, Daniel. Una lectura: una vida..., Buenos Aires: Ampersand, 2017.

Ludmer, Josefina. «El tiempo del día». Aquí América latina: Una especulación. Buenos Aires: Eterna Cadencia, 2010, p. 23. . «Literaturas postautónomas 2.0». Propuesta Educativa, vol. 2, n 32, noviembre de 2009, pp. 41-45.

Mairal, Pedro. «Prólogo» Teoría de la gravedad, de Leila Guerriero, Barcelona: Libros del Asteroide, 2019, pp. VII-XI. 
Patán, Lulio. Entrevista: Leila Guerriero de El País sobre su estilo de periodismo narrativo [Es la hora de opinar]. Recuperado de

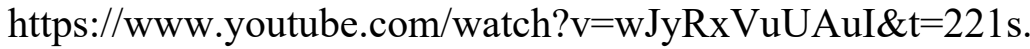

Ramos, Julio. «IV: Limites de la autonomía: periodismo y literatura». Desencuentros de la modernidad en América Latina: Literatura y política en el siglo XIX. Caracas: Fundación Editorial El perro y la rana, 2009.

Real Academia Española. Diccionario de la lengua española. Espasa, 2021.

Sarlo, Beatriz. «El aura subjetiva». La intimidad pública. Barcelona: Seix Barral, 2018, pp. 97-121.

Sibilia, Paula. La intimidad como espectáculo. Buenos Aires: Fondo de Cultura Económica, 2008.

. (09 de octubre de 2016). En Paula Sibilia: la intimidad es un espectáculo / Entrevistada por José Soto Galindo. El Economista: https://www.eleconomista.com.mx/opinion/Paula-Sibilia-la-intimidad-es-un-espectaculo-20161010-0001.html

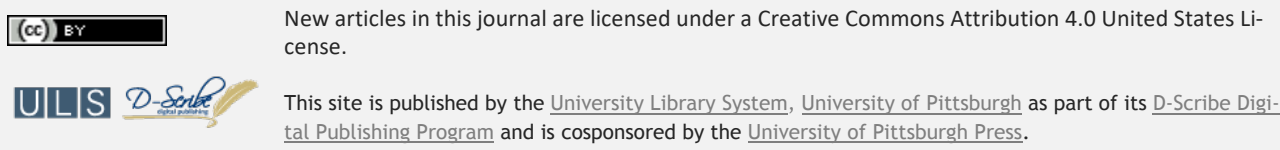

